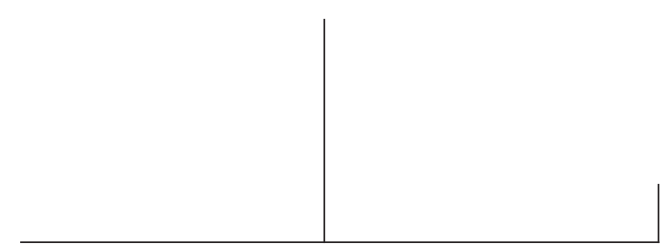

Rev. Latinoam. Psicopat. Fund., III, 2, 9-25

\title{
A clínica da depressão: questões atuais
}

\author{
Manoel Tosta Berlinck \\ Pierre Fédida
}

\begin{abstract}
A psicoterapia com pacientes que encontram-se sob efeito de antidepressivos revela que estes são relativamente eficazes na inibição de sintomas considerados típicos da depressão. Porém, ao mesmo tempo, sintomas considerados típicos da melancolia não são afetados por esses medicamentos.

Nem a longa e rica tradição psiquiátrica nem a psicanalítica estabelecem uma diferença específica clara entre depressão e melancolia, tratando-as, na maior parte das vezes, como fazendo parte de um mesmo campo semântico e, por isso, sendo utilizadas como sinônimos. Esta tendência culmina em manuais de psiquiatria, como o DSM-IV e o CID-10, em que o transtorno bipolar é denominado maníaco-depressivo. A melancolia fica, assim, dissolvida na depressão.

Partindo desta constatação clínica, este trabalho estabelece uma diferença específica entre depressão e melancolia e descreve o campo semântico próprio da depressão.
\end{abstract}

Palavras-chave: Psiquiatria, psicanálise, depressão, melancolia, psicoterapia 


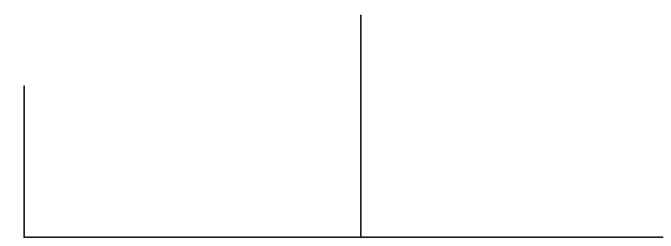

\section{Introdução}

Apesar da longa e rica tradição de estudos sobre a melancolia, inaugurada no Ocidente com Aristóteles (1999), retomada, na modernidade, com o estudo de Robert Burton, e, depois disso, prosseguindo como tema central das nosografias e nosologias psiquiátricas até os anos 70 do século $\mathrm{XX}$, os mais recentes Manuais de Psiquiatria - o Manual Diagnóstico e Estatístico de Transtornos Mentais, 4a edição, conhecido também como DSM-IV, da Associação Psiquiátrica Americana, e a Classificação de Transtornos Mentais e de Comportamento da CID10, da Organização Mundial da Saúde, com sede em Genebra, Suíça - dissolvem a melancolia na depressão (Peres, 1996; Pessotti, 1999). Assim, nos capítulos sobre os transtornos do humor desses Manuais, os denominados "transtornos bipolares" não se referem mais à melancolia-mania, mas à depressão-mania.

Outras publicações de saúde mental, como The Harvard Mental Health Letter (1990), reconhecem dois tipos de transtornos do humor ou afetivos: a depressão e o transtorno maníacodepressivo. A depressão pode ocorrer como depressão maior ou como forma mais leve, denominada distimia. A desordem bipolar pode, também, apresentar forma mais suave, denominada ciclotimia.

Essa dissolução é particularmente notável a partir dos anos 80, pois, até então, a psiquiatria dedicava sua atenção à melancolia, ainda que esta incluísse a depressão. De fato, como observa Mário Pereira (1999), a psiquiatria alemã nunca realizou uma distinção entre melancolia e depressão, tratando as duas indistintamente. Freud, por exemplo, dedicou sua atenção à melancolia fazendo pouquíssimas referências à depressão. Observa-se em seus textos que depressão e melancolia não precisam ser distinguidas de forma 


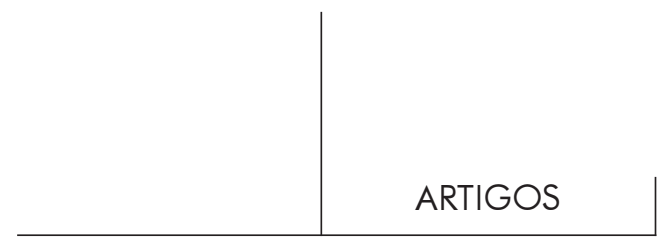

clara e precisa, ainda que, em "Luto e melancolia" ([1915] 1969) tenha estabelecido uma nítida diferença. Conceber a depressão como luto talvez seja o caminho mais claro e preciso para se pensar a melancolia como afecção psíquica específica.

Assim compreendida, a depressão tem sido objeto constante de estudo da psiquiatria, quando essa se empenha na investigação da melancolia, sendo, assim, apressado afirmar tratar-se de manifestação psicopatológica da contemporaneidade, mesmo se reconhecendo, atualmente, uma verdadeira epidemia dessa doença. Hoje, o denominado melancolia passa a ser nominado depressão, conservando uma indistinção reveladora de grandes dificuldades em se estabelecer diferenças específicas entre essas manifestações.

Entretanto, já Hipócrates (1983), em seu aforismo 23, seção VI, afirmava que "pacientes com medo ou tristeza de longa duração são sujeitos à melancolia", estabelecendo, assim, nítida distinção entre essas duas afecções.

Mas quais as razões que levaram a psiquiatria contemporânea a deixar de lado a melancolia e dar relevância à depressão?

Seria insuficiente afirmar que esta dissolução se deve, em grande parte, à proliferação de antidepressivos. A crescente produção dessas drogas responde, notadamente, a uma demanda que vem se acentuando, de forma notável, a partir dos anos 70. A depressão é, hoje, uma doença assolando, de forma particularmente notável, os países ocidentais mais ricos e onerando não só os sistemas de saúde como a produtividade do trabalho. Por outro lado, os antidepressivos, como o nome indica, são bastante eficientes no tratamento da depressão, mas não são antimelancólicos. É a partir da disseminação do consumo de antidepressivos, por clientes que estão em tratamento psicoterapêutico, que se observa uma clara diferença psíquica entre depressão e melancolia. Estes pacientes, invariavelmente, saem da depressão, mas permanecem com sintomas melancólicos. Há, portanto, depressão na melancolia. Porém, enquanto a primeira pode ser vista como estado, a segunda pode ser caracterizada - tal como Freud o fez - como neurose narcísica onde o conflito intrapsíquico ocorre entre as instâncias do ego e do superego implicando o sujeito na culpa. Em outras palavras, enquanto a depressão é estado de luto muito primitivo, manifestando-se sem culpa, a melancolia é neurose composta de conflito, culpa e depressão. A psiquiatria regida pelo DSM-IV e pelo CID-10 não reconhece, por sua vez, a existência da culpa ou até mesmo o conflito inconsciente que caracteriza a neurose. Por que, então, admitir a existência da melancolia?

Assim, será que a dissolução da melancolia na depressão estabelece uma equivalência entre esses dois nomes, equivalência que encontra apoio na literatura de ficção e no senso comum, que sempre trataram as duas como sinônimos, ou será que cria um novo "transtorno" que não corresponde às tradicionais denominações? Será, ainda, que essa dissolução corresponde, pura e simplesmente, a uma exigência objetificante dos tratamentos de transtornos mentais? 


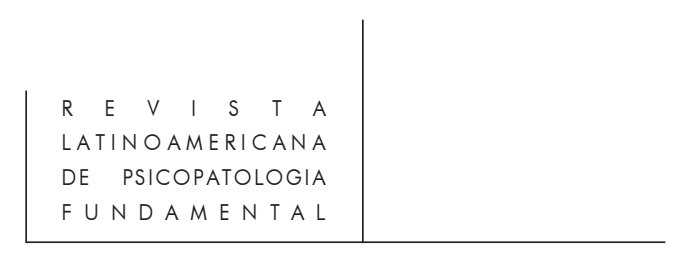

Para levar em consideração estas questões, é necessário, então, em primeiro lugar, retroceder e tentar estabelecer campos semânticos específicos para a depressão e para a melancolia e pensar, em seguida, o que se dissolve na atual concepção de depressão contida nos Manuais citados para, finalmente, se formular as consequiências dessa dissolução, tanto para a psiquiatria como para a psicanálise. Este esforço de diferenciação afasta momentaneamente a Psicopatologia Fundamental da psiquiatria, da psicanálise e do senso comum, como parte de cuidadosa observação clínica e procura atender exigência científica que está sempre em busca de clareza e especificidade visando aprofundar o conhecimento. Aqui, entretanto, será dado, apenas, o primeiro passo procurando especificar o campo semântico da depressão. As referências à melancolia serão as mais sucintas e só ocorrerão à medida que for necessário para este trabalho de especificação.

\section{O campo da depressão}

A depressão, nas palavras de Daniel Delouya (1999), não figura entre os quadros clínicos clássicos da psicanálise e nunca ocupou um lugar de destaque entre seus temas. Como já se disse, Freud dedicou sua pena à melancolia tratando-a sempre como neurose narcísica, mesmo após a adoção da expressão genérica psicose e a atenção às configurações clínicas da depressão surge, na psicanálise, em associação ao luto e às patologias borderline ou estados-limite pelas quais ela vem manifestando, desde os anos 50, um crescente interesse.

Além disso, seria precipitado afirmar que a depressão constitui, na psicanálise pós-freudiana, uma estrutura clínica, como o são o recalque, a recusa da realidade e a negação ou foraclusão.

Desde logo parece prudente caracterizar a depressão como um estado se manifestando em qualquer estrutura clínica. Porém, não seria correto dizer que existe uma depressão neurótica, uma depressão perversa, uma depressão psicótica. A depressão seria uma só ocorrendo nas diversas estruturas clínicas.

Do que se trata quando se trata, então, da depressão, já que não se trata de uma estrutura clínica?

Como caracterizar este estado senão pela letargia, por uma lentificação, uma insensibilização da sensorialidade? A depressão se manifesta por apatia, tristeza e sensações de impotência e desesperança (Grinberg, 1983). O fenômeno-alvo psicopatológico visado na letargia e, portanto, na depressão, é mesmo a condição vegetativo-vital, nosologicamente inespecífica (Bucher, 1979). Nela, a intensidade das cores esmaece, assim como o claro-escuro, dando lugar a uma tonalidade cinza, sem contraste. Os cheiros param de ser percebidos, as texturas deixam de ser registradas, os sons ficam amortecidos e podem até desaparecer. O processo digestivo 


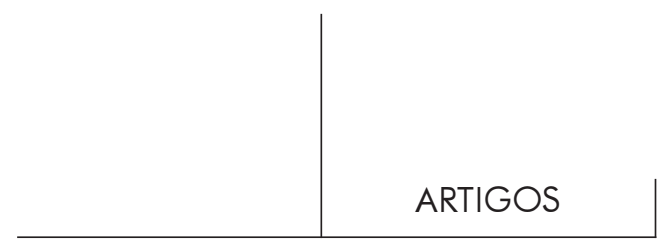

fica prejudicado e o corpo passa a ficar pesado. Os movimentos corporais ficam lentos, os pés se arrastam. Em suma, o corpo penetra um estado de insensibilização da sensorialidade.

A depressão, entretanto, varia de intensidade. Pode tomar a forma de um estado denominado, às vezes, pela psiquiatria, depressão subclínica, assim chamado por não ser notado pelo clínico, a não ser por um complexo de sintomas psicovasomotores, complexo este que se distingue do reconhecido amuo depressivo. São típicas deste estado as seguintes queixas: opressão no tórax, pesadelos, pressão no crânio, sinusite, dores de cabeça, tonteiras, distúrbios do sono e da potência sexual. Pode, no outro extremo, se manifestar na catatonia ou na doença do sono, ambas de grande intensidade (Bucher, 1979; Sacks, 1998). Essas manifestações somáticas só são possíveis dada a natureza da alteração da condição vegetativo-vital desse estado psíquico. De fato, a letargia da sensorialidade é acompanhada por alteração no sistema vegetativo-vital associando-se a uma série de manifestações somáticas constituindo, em seu conjunto, a linguagem própria da depressão.

Assim concebida, é fácil perceber que a depressão não se manifesta só no humano. Outros animais, e até vegetais, também apresentam letargia e alteração da condição vegetativo-vital. O equivalente animal e vegetal da depressão seria a hibernação, um estado letárgico, com evidentes alterações na condição vegetativo-vital, apresentado tanto pelo animal como pelo vegetal enquanto dura o inverno.

Porém, ao contrário do ocorrido com as outras espécies, como quer Freud (1987), a catástrofe glacial constitui o "momento" da passagem da animalidade para a humanidade e a depressão é estado acompanhando essa transformação. Com a catástrofe glacial, há uma reviravolta no ambiente, seguida pela perda de contato com a regularidade sexual e pelo desaparecimento do objeto primitivo de satisfação. Essas ocorrências lançam o humano a uma situação de insuficiência muito primitiva denominada desamparo (Pereira, 1999; Rocha, 1999) e produzem dor, depressão e angústia, estados solicitando, junto com a ameaça de extinção da espécie, mutação no sistema imunológico visando a sua sobrevivência. Nessa perspectiva, a catástrofe não é só uma reviravolta que ameaça a existência da espécie. É, também, condição de ocorrência de mutação implicando, neste caso, a constituição de um aparelho psíquico, parte do sistema imunológico permitindo ao humano enfrentar um mundo sem contato com a regularidade sexual e sem o objeto da satisfação, ou seja, um ambiente adverso, com escassos recursos para a sobrevivência, onde a espécie encontra-se permanentemente ameaçada.

A depressão seria, assim, uma figura e um estado do corpo angustiado e dolorido pela catástrofe que produz a perda do objeto primitivo de satisfação e a correspondente perda de contato com a regularidade sexual assegurada, primitivamente, pela sensorialidade. (Freud, 1938) 


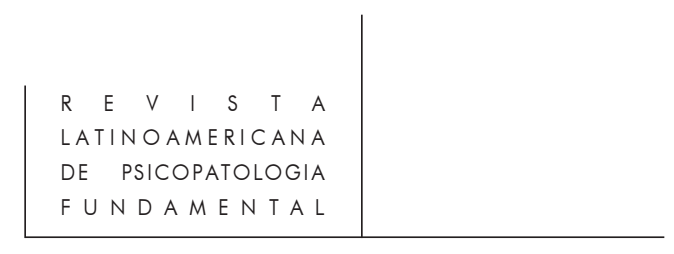

Chocado pelo congelamento da crosta terrestre, com sua sensorialidade extremamente reduzida pelo frio e sem poder reconhecer a fêmea fértil, o animal humano enfrenta situação crítica para a sua existência estando submetido a um estado de ausência e desamparo. Para suportar a dor e a angústia causadas pela ausência do objeto de satisfação e a insuficiência gerada pelo vazio provocado pela ausência do mesmo objeto, o humano reage com insensibilização da sensorialidade e procura um leito para hibernar. As cavernas, essas mesmas grutas registrando em suas paredes as primeiras manifestações representativas do humano, passam, então, a ser utilizadas, e lá o animal pode se entregar à manifestação do estado letárgico em seu corpo.

Mas pode apresentar, também, incessante atividade movida pela depressão, buscando um parceiro que lhe dê a sensação de estar reencontrando o objeto perdido. Essa atividade sem fim é produzida, no deprimido, por uma sensação de vazio impossível de ser preenchida, mas que, ao mesmo tempo, não pode ser acolhida como própria a não ser com uma intensa sensação de dor e de angústia. O medo da dor - provocada pela perda ocorrendo na catástrofe - afasta o humano de sua própria depressão, conservando-a como bem indesejável, impossível de ser apropriado e permanecendo presente no intenso esforço de torná-lo ausente, manifestando-se pela atividade em busca de um objeto de satisfação. É assim, por exemplo, na alma dos românticos, cultores do vazio da depressão por meio de atividades almejando objetos de satisfação. No romantismo não há uma caverna onde pode ser encontrado um leito para a depressão. Os românticos perambulam pelas cidades, em tavernas, cavernas habitadas por outros, agitadas, animadas por um persistente vazio. Essa manifestação figura a presença excessiva do ausente, um corpo invasor impedindo a constituição da organização narcísica do vazio onde é possível encontrar uma temporalidade própria e romper o estado de alienação que se abateu sobre o fazer, deixando de emprestar o corpo para o que se foi. O luto impossível do objeto primitivo de satisfação produz a depressão interminável onde o corpo se empresta ao que foi embora, pratica em si seus gestos, encarna-o. Abandonar seu próprio gesto para assumir o alheio e alienar-se nele, ausentificar-se nele, desencarnar-se nele - tudo para negar que já se foi, lança o sujeito numa depressão sem tempo para terminar.

$\mathrm{Na}$ depressão o tempo se fecha e a letargia pode durar muitos anos, como ocorre na doença do sono, detalhadamente estudada por Oliver Sacks (1998), e se manifestar pela insensibilização sensorial correspondendo a uma parada, imobilidade, fisgo e fixidez do corpo, em suas variadas formas, podendo até se manifestar por uma agitação motora e uma irritabilidade, como ocorre em crianças deprimidas. A inanimação, então, nem sempre é do corpo, mas também da sensorialidade, ou melhor, da condição vegetativo-vital.

Partindo dos limites hibernais que, no humano, podem ser identificados como depressão anaclítica e como catatonia (ainda que esta seja um sintoma da esquizo- 


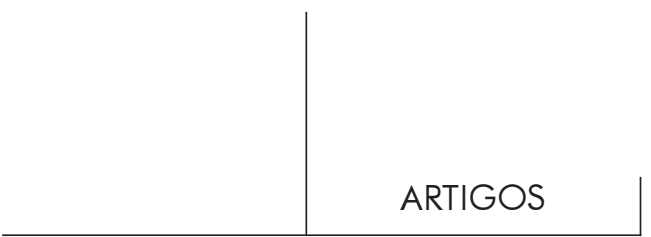

frenia), a depressão pode ser caracterizada, então, como um estado inanimado do vivo ocorrendo graças à catástrofe glacial e repetindo-se toda vez que o frio e a neve visitam certas regiões do globo (e, depois, visitam o próprio aparelho psíquico). Aí, o crescente resfriamento do ambiente produz, primeiro, uma desvitalização sensorial do vivo: os frutos amadurecem e caem das árvores, as folhas secam e se tornam amarelas, os animais vão ficando desanimados como os humanos, até a ocorrência da primeira nevada. A partir daí, as árvores e arbustos desnudados de suas folhas conservam uma inanimação parecida com a morte, sendo conservadora da vida; os animais desaparecem tendo se recolhido aos seus abrigos carregados de alimentos acumulados durante o verão e o outono anteriores e, a partir daí, são seus corpos habitados por um estado de lentificação sensorial própria da hibernação; e até os humanos, sempre ativos e acumuladores, são, muitas vezes, obrigados a diminuir seu ritmo e suportar o silêncio e a escuridão advindos com o frio e a neve.

A depressão é, assim, um estado de vazio, de ausência, correspondendo a um tempo parado expondo o lugar e espaço, o fundo em relação ao qual ecoa o tempo da psique e permitindo dizer que ela define-se por uma posição econômica que concerne a uma organização narcísica do vazio segundo uma determinação própria para a inalterabilidade tópica da psique.

O aparelho psíquico seria, portanto, a parte do sistema imunológico constituída, no humano, durante a catástrofe glacial. Trata-se de uma organização narcísica do vazio correspondendo à perda do objeto de satisfação, à perda de contato com a regularidade sexual e visando proteger o humano da dor, da própria depressão e da angústia.

Esta não é uma estrutura psíquica porque é o estado próprio à estruturação do aparelho psíquico, permitindo dizer que não há estado humano a-depressivo; que a depressão, por ser constitutiva do psiquismo e porque este peculiar aparelho prossegue, continuamente, se constituindo, caracteriza o humano.

A depressão seria, então, um estado durando o tempo necessário para que o vazio inanimado do vivo se constitua como organização narcísica e retorna toda vez que o psiquismo solicita uma restauração de seu narcisismo. Como este está constantemente ameaçado, tanto por forças externas como internas, a depressão está invariavelmente presente. O humano, como se sabe, não suporta por muito tempo o contato com a dura realidade e um dos recursos à sua disposição para se proteger desse contato tão frustrante e ameaçador é a depressão.

O aparelho psíquico, a organização narcísica do vazio, é o local onde ocorre, também, a brotação da angústia e da sensorialidade no fim do ciclo hibernal. $\mathrm{O}$ psíquico, constituído na íntima dependência do meio ambiente e das cargas condicionadas pela situação vivencial, é o campo do endógeno constituído graças a um complexo de ações reativas diante de ameaças ecossistêmicas. Como observa 


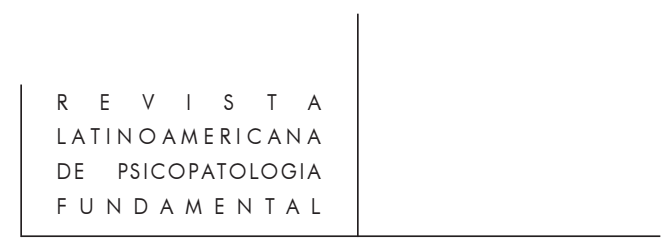

Tellenbach (1999), endon designa uma origem e, neste sentido, também uma procedência.

O conceito de endógeno, assim como a diferenciação entre endógeno e exógeno, foi introduzido na psiquiatria por Moebius, em 1892. Endogenidade é, para esse autor, um predicado do degenerativo. Diz Moebius que "só sob a condição de que seja degenerado, é possível que alguém sofra de uma doença endógena". Com isso coloca desde o começo o endógeno em proximidade imediata com a catástrofe, a insuficiência e o somático. Estreitamente ligado ao conceito de "disposição", o endógeno aparece como uma região etiológica pertencente ao território do soma, mas sem qualquer outra especificação à qual são atribuídas as alterações psíquicas denominadas psicoses endógenas. A psiquiatria viu claramente o peculiar e inequívoco de tais psicoses, e as designou acertadamente com o termo endógenas, mas em seguida as "somatizou" sem refletir direito sobre o endógeno.

$\mathrm{Na}$ realidade, considera-se o endógeno como algo somatógeno sem que isso esteja comprovado e, no curso do tempo, espera-se poder iluminar o campo obscuro de sua procedência como um campo causal somático. Porém, até então, o endógeno permanecerá absolutamente como criptógeno, ou seja, como um conceito negativo.

Tellenbach (1969), entretanto, revela o conteúdo positivo definível do endógeno dizendo que:

Com o termo endon compreendemos a instância espontânea e original manifestandose em certas formas fundamentais do ser-do-homem, e que tais formas fenomênicas tanto em momentos de saúde como, e com maior razão, em momentos de psicose -, são o que designamos endógeno. (p. 30)

Neste sentido, o endógeno é o involuntário que caracteriza o ser-do-homem em sua singularidade, mantendo sua própria identidade no decurso temporal. Tratase, pois, da estruturação e manifestação antecipadas da singularidade, mantendo sua forma específica através de formações e transformações no decurso do tempo. Podemos dizer, com Tellenbach, que endógeno é tudo o que no acontecer vital do homem se produz sempre de novo como unidade da forma fundamental.

O aparelho psíquico é, assim, junto com a dor, a depressão e a angústia provocadas pela catástrofe, a primeira formação do endógeno, ou seja, é o endógeno constituindo-se na depressão como organização narcísica do vazio.

Entretanto, em algum momento dessa hibernação primitiva, dessa depressão primitiva e fundamental onde a sensorialidade encontra-se inanimada e viva, o humano começa a sofrer uma brotação da sensorialidade podendo ser denominada autística. A bidimensionalidade sensorial aí se manifestaria, produzindo movimentos corporais repetitivos e padronizados. O autismo seria uma fixação nesse estado onde, na organização narcísica do vazio, haveria uma repetida brotação da sensorialidade, sem se articular com imagens e onde os sons só ecoariam produzindo falas ecolálicas. 


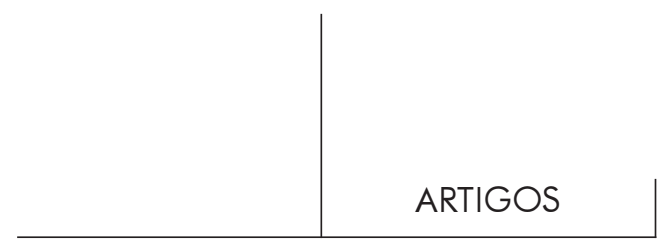

Nesse sentido é possível dizer que o autismo é um auto-erotismo sem Eros e, ao mesmo tempo, o paradigma do aparelho psíquico - uma organização narcísica do vazio onde, em primeiro lugar, só haveria manifestações da sensorialidade (Berlinck, 1999). Mas a ação de Eros pode prosseguir se houver condições favoráveis, e as manifestações da sensorialidade podem se transformar em sensações cada vez mais vivas e em sonhos. Ocorrem, assim, as primeiras manifestações oníricas - psicoses controladas, nas palavras de Freud. A alucinação fantasmática caracterizando o sonho como psicose controlada seria, então, a manifestação imaginária, propriamente psíquica, aparecendo na saída da depressão hibernal e, por isso, manifestação endógena do vivo inanimado, no acordar da sensorialidade, que é autística. A passagem das primitivas manifestações da sensorialidade para o sonho e, mais tarde, para a fantasia, é uma ação de Eros, ou seja, se constitui como um movimento primitivo em direção a e na produção alucinada de um objeto sucedâneo do que foi perdido na catástrofe. Este novo estado afetivo do aparelho psíquico, onde brotam sensações e imagens, denomina-se depressividade, um estado primaveril do psiquismo, onde o vivo deixa de ser inanimado para manifestar, com pujança, sua sensorialidade e seu imaginário.

Na depressividade, o emergente é a sensorialidade até então embotada pela letargia e, assim, a condição vegetativo-vital sofre uma alteração. As cores, os sons, as tonalidades, as texturas, os aromas, os gostos são, agora, percebidos com crescente vivacidade. $\mathrm{O}$ sonho e a fantasia se fazem presentes, marcados por sentimentos, por afetos, as manifestações do erotismo fazendo parte da sensorialidade.

Pouco se sabe sobre esse trabalho de Eros permitindo a passagem da depressão para a depressividade, mas ele pode ocorrer "naturalmente", ou seja, obedecendo a um ciclo vital próprio do organismo, ou pode ser induzido por antidepressivos. De qualquer forma, a passagem da depressão para a depressividade coloca a questão do tratamento psicoterapêutico deste estado pois, sem esta transformação, pode ocorrer uma cronificação.

Coloca, também, o problema do estatuto da realidade no psiquismo bem como a maneira como o humano com ela se relaciona. A reviravolta provocada pela glaciação promove, em última instância, um desligamento da maneira como o hominídeo se relacionava com a realidade. A construção do aparelho psíquico, com sua posterior erotização, criando a endogenidade, o mundo dos objetos, a psicose endógena controlada e as ligações tanto com o mundo interno como com o externo, modifica radicalmente a relação com a realidade, deixando de ter existência independente das representações. Este processo é fundamental para os mecanismos de defesa em constituição: o recalque - Verdrangung, a recusa - Verleugnung e a negação ou foraclusão - Verwerfung.

O desligamento da maneira como o hominídeo se relacionava com a realidade antes da catástrofe glacial, a constituição do aparelho psíquico e sua subseqüente 


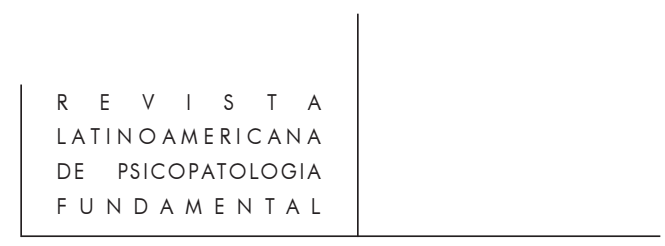

erotização é a mais primitiva recusa da realidade provocada pela dor. Essa reviravolta leva, como já foi dito, à depressão e à depressividade que, se por um lado, protegem o hominídeo da realidade ameaçadora, o preparam, também, para o relacionamento humano com a realidade, intermediado pelo mundo interno próprio ao psiquismo. A partir daí, a depressão é o estado que afasta o humano de sua relação com a realidade e, ao mesmo tempo, fornece condições para que este mesmo humano possa suportar a relação com a realidade, pois esta é responsável pela dor, pela perda de objetos levando à depressão e à angústia.

Essa mesma recusa da realidade é fundamental para a perversão, ainda que esta só se constitua a partir da relação do sujeito com a mãe narcisista que proporciona o fetichismo. Em outras palavras, a recusa da realidade, provocada pela dor, levando à depressão e à angústia e sendo fundamental para a constituição do aparelho psíquico e o relacionamento humano com a realidade é objeto de reviravolta com o fetichismo tentando, assim, se livrar tanto da dor como da depressão e da angústia.

Coloca, finalmente, uma dificuldade diagnóstica, pois a saída da depressão, a depressividade, se assemelha a um estado maníaco levando o clínico a supor que se encontra diante de um transtorno bipolar. Na passagem da depressão para a depressividade observa-se euforia e motilidade. Porém não se observa nem o conflito entre ego e superego, a identificação com o Ego Ideal, nem a manifestação da crueldade provocada pela culpa levando freqüentemente à destrutividade e autodestrutividade típicos da melancolia-mania. Muitas vezes o clínico é conduzido à confusão diagnóstica porque na depressividade também se observa angústia e medo provocados não pela culpa, mas pelo intenso contato com a vida, por meio da mesma sensorialidade que se encontrava num estado de letargia. A culpa não se constitui com a perda do objeto primitivo de satisfação nem com a perda de contato com a regularidade sexual, não sendo tão primitiva como a depressão. Esta se manifesta independentemente da culpa e é mitigada pela constituição do psiquismo onde habita o objeto a, causa do desejo. A culpa, por sua vez, é dívida contraída pelo humano por ocasião do assassinato e devoração do pai primitivo encerrando a fase patriarcal. Esta segunda grande catástrofe abatendo-se sobre o humano produz mutação que corresponde ao aparecimento do superego no aparelho psíquico, o herdeiro do pai primitivo, caracterizando-se por ser sábio, forte e brutal. Compreende-se, assim, a famosa pergunta de Aristóteles (1998):

Por que razão todos os que foram homens de exceção, no que concerne à filosofia, à ciência do Estado, à poesia ou às artes são manifestamente melancólicos, e alguns a ponto de serem tomados por males dos quais a bile negra é a origem, como contam, entre os relatos relativos aos heróis, os que são consagrados a Hércules? (p. 81) 


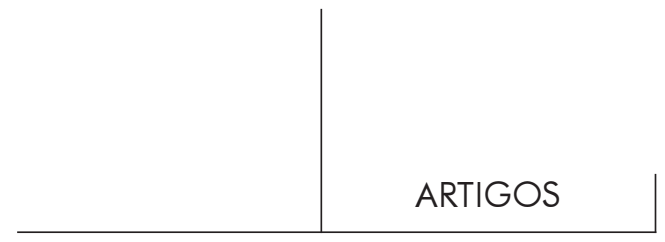

cuja resposta proposta por Freud é: a existência do superego em conflito com o ego.

De fato, os melancólicos são deprimidos mas são, também, sábios, fortes, brutais e culpados. É conhecida a atração que sofrem pelo Ego Ideal com quem se identificam. Estão constantemente sendo atraídos pela fama e pela glória que, freqüentemente, não alcançam devido ao seu ego considerado pequeno e suficientemente insignificante. Quando alcançam essas posições tão almejadas com freqüência tendem a destruir, com crueldade, a situação arduamente alcançada.

$\mathrm{Na}$ melancolia, observa-se conflito intrapsíquico e recalque diferentes do observado na histeria e na neurose obsessiva. Naquelas, o conflito se dá entre as instâncias mais primitivas do id e do ego. Na melancolia, o conflito ocorre, como já foi dito, entre as instâncias do ego e do superego e é regido pela culpa. Não há, pois, como considerar a melancolia como uma psicose ainda que seja necessário reconhecer que ela se encontra próxima tanto da neurose obsessiva como da paranóia e da esquizofrenia. (Lambotte, 1997; Roudinesco \& Plon, 1998)

Assim, estabelecida a diferença específica entre depressão e melancolia, torna-se claro que a psicoterapia da segunda deve levar em consideração a sabedoria, a força, a crueldade e a culpa, ou seja, a identificação com o Ego Ideal. Mas deve, também, tratar da depressão do melancólico sem confundir depressividade com mania.

\section{O tratamento psicoterapêutico da depressão}

Já foi observado, anteriormente, que diante da catástrofe glacial, o animal, perdendo contato com o objeto de satisfação e com a regularidade sexual, busca um ambiente favorável para a sua depressão. Esse ambiente primitivo e também fundamental para a constituição do aparelho psíquico, muito provavelmente foi encontrado em cavernas onde alimentos eram acumulados, essas mesmas grutas onde, mais tarde, o humano, saindo da depressão, pôde registrar, nas paredes, suas primeiras manifestações imaginárias.

Pacientes deprimidos, quando conseguem se afastar de uma irritabilidade ativa com evidentes alterações da sensorialidade, e entram em contato com a sua inanimação, buscam um lugar tranqüilo e protegido, junto a alguém capaz de cuidar deles, para se entregarem ao sono e à prostração. Esses pacientes revelam, freqüentemente, uma identificação vampiresca associada ao vazio e à necessidade que sentem de serem preenchidos por conteúdos alimentadores e imunitários vindos de fora; podem relatar a necessidade por "sangue novo" e sua capacidade de atrair "jovens puras e virgens" para serem sugadas a fim de se sentirem animados. A depressão pode levar, então, a um comportamento aditivo manifestando-se por meio de certos comportamentos de deglutição visando preencher o vazio, aplacar a ausência. 


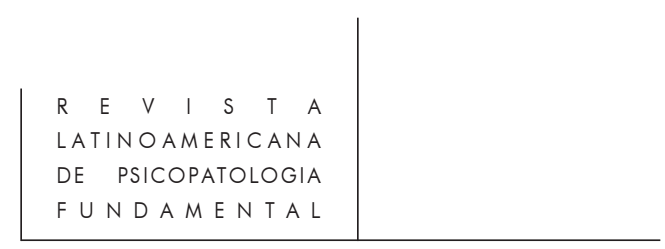

Assim, sem sombra de dúvida, para tratar a depressão o psicoterapeuta deve oferecer ao paciente uma caverna placentária onde haja um leito. A referência à placenta, aqui, não deve remeter à mãe ou ao útero, mas a uma caverna onde o psiquismo em formação inanimada encontre alimentos e, principalmente, recursos imunitários possibilitando a passagem da depressão para a depressividade.

O psicoterapeuta deve se permitir ser invadido pela lentificação da sensorialidade vinda do paciente, sem perder contato com sua própria depressividade.

É exatamente aqui onde reside o desafio colocado pelo tratamento psicoterapêutico da depressão. Como ela é o tempo necessário para a construção e reconstrução da organização narcísica do vazio, necessitando leito num ambiente placentário, a primeira condição desse tratamento é o ambiente. Se este não for suficientemente cavernoso, alimentador e seguro, o paciente deprimido pode se sentir muito ameaçado, pois se encontra num estado de desamparo, com graves insuficiências imunológicas (Pereira, 1999). Essa ameaça pode impulsioná-lo a comportamentos vampirescos assemelhando-se a uma adição. Nestes casos, pode ocorrer de o psicoterapeuta ser identificado com uma fonte de substância e energia capaz de nutrir a organização narcísica do vazio do deprimido, quando o tratamento é direcionado visando encerrar esse interminável vazio e o solilóquio com o ausente. A consequiência desse tipo de transferência é que o psicoterapeuta pode sentir, durante o tratamento, uma anemia psíquica crescente, com desânimo, irritabilidade, falta de apetite de conteúdos psíquicos, fraqueza etc. Entretanto, não é freqüente se manifestar aí a letargia que quase sempre atinge o psicoterapeuta no tratamento da melancolia levando-o a uma sensação de peso e insensibilização letárgica - uma espécie de estado de morte. Em segundo lugar, o tempo em que o paciente permanece na depressão também deve ser levado em consideração pelo psicoterapeuta, pois se o outro, ao ter partido, tornou-se excessivamente presente no vazio, é necessário encontrar mais uma vez uma temporalidade própria possibilitando a saída do estado hibernal. A saída induzida do estado de depressão pela ação de antidepressivos, ou por uma atividade psicoterapêutica, pode provocar um efeito inibidor na depressividade - por não respeitar a temporalidade nascente e levar o paciente ao suicídio.

Além disso, como a escuta psicoterapêutica ocorre num estado de depressividade, a fala do paciente, regida pela regra fundamental, penetra transferencialmente o psiquismo vazio do psicoterapeuta fazendo brotar, nesse estado, sensações, imagens, sonhos e fantasias. Assim, o psiquismo do psicoterapeuta seria uma caverna placentária em depressividade, onde a brotação ocorre por transferência do paciente deprimido. Entretanto, antes dessa ocorrência, o transferido para dentro do psiquismo do psicoterapeuta, na depressão, é a letargia sentida no corpo, podendo suscitar muita angústia. Dizer ao paciente, nessa oportunidade, que ele está ameaçando o psicoterapeuta de morte - tratando-se literalmente de verdade, já que é tam- 


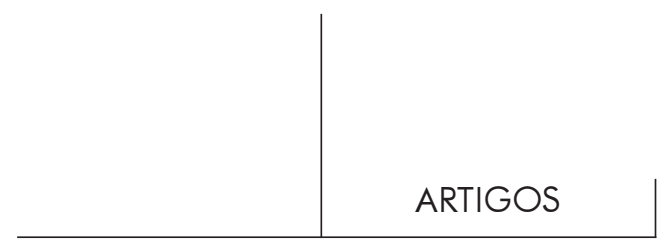

bém a transferência de uma reatualização da catástrofe glacial - pode ser muito útil para afastar a lentificação da sensorialidade do psicoterapeuta, mas pode, da mesma forma, deixar o paciente sem leito nem placenta para a sua depressão. Logo, o desafio perfilando-se no tratamento psicoterapêutico da depressão é o da possibilidade do psicoterapeuta atravessar o inverno transferencial sem perder contato com a sua própria depressividade.

O tratamento psicoterapêutico da depressão exige, portanto, um tempo, um verdadeiro ciclo que corresponde à organização narcísica do vazio e às manifestações que aí ocorrem.

\section{Uma espécie sem depressão?}

A depressão só adquire crescente importância à medida que as exigências do mundo de hoje são a atividade, a eficiência prática e pragmática, a produção material e o consumo, a ausência de um constante retorno da tradição naquilo que se manifesta no presente. Em outras palavras, o que se ensaia na atualidade é um mundo sem catástrofe e, por isso, sem depressão.

A ausência de catástrofe supõe um ambiente com variações controladas. O aprimoramento constante do conhecimento científico e o avanço tecnológico têm proporcionado ao humano, crescente e cada vez mais complexo domínio sobre as variações ambientais. Além disso, agentes nocivos - tanto micro como macro organismos - têm sido combatidos com instrumentos cada vez mais eficazes. Esse crescente controle do humano sobre o ambiente tem sido acompanhado por sucessivas revoluções agrícolas visando a crescente produção de alimentos. Dessa forma, a ameaça malthusiana expressa pela reprodução geométrica de elementos da espécie e pela reprodução aritmética dos recursos naturais necessários para a sobrevivência não tem sido observada. A abundância e a riqueza têm avançado sobre a face da terra, com exceção da África, o continente até agora abandonado.

Se compararmos a situação da Grécia Antiga, berço da civilização ocidental, com a atualmente existente, facilmente tomaremos consciência da crescente complexidade e eficácia da regulamentação das relações humanas visando evitar guerras, conflitos, brigas e assassinatos. A questão da segurança civil é, hoje, um dos mais relevantes assuntos ocupando os humanos e, muito provavelmente, ela deverá aumentar nos tempos que virão.

Essas conquistas antidepressivas e antiangustiantes têm sido acompanhadas por crescente evitação e desalojamento de todos os símbolos relacionados com a morte e a presença do ausente. Neste sentido, o mais generalizado mecanismo é, sem dúvida alguma, o recalque da tradição e o desinteresse por aquilo que nos liga a nossa herança. Os defuntos são rapidamente enterrados em cemitérios cada vez mais 
$R \quad E \quad V \quad$ I $S$ T

LATINOAMERICANA

DE PSICOPATOLOGIA

F UNDAMENTA L

discretamente localizados no espaço urbano ou, então, são cremados. Quando o velório é inevitável, o morto é preparado como se ainda estivesse vivo, como acontece, por exemplo, na Califórnia, E.U.A., e o ritual é sempre o mais breve possível.

Além disso, cada vez mais, as pessoas se ocupam com miríades de objetos internos e externos evitando, assim, o contato com a falta, o vazio, a ausência e a própria depressão. $\mathrm{O}$ ritmo cotidiano fazendo-nos muito parecidos com o coelho em Alice no país das maravilhas estimula intensa atividade pseudoprodutiva organizadora e ordenadora de um mundo sem abismos.

Os antidepressivos, cada vez mais eficazes, à medida que não apresentam efeitos colaterais, vêm coroar esse mundo onde o humano procura se afastar, cada vez mais, da depressão.

Nesta perspectiva colocada pela contemporaneidade, não se trata mais de propor que a clínica psicoterapêutica da depressão se refere a uma perspectiva, uma abordagem clínica levando em consideração o modo de existência do sujeito. Tratase de indagar a que sujeito se refere, na contemporaneidade. A resposta a esta pergunta é, evidentemente, a de que existem múltiplas concepções de sujeitos no mundo de hoje e, para muitos, a depressão é uma doença devendo ser tratada com antidepressivos.

Mas na abundante multiplicidade da subjetividade na contemporaneidade há, ainda, lugar para um "modo de existência do sujeito do inconsciente"?

É bom lembrar, aqui, que o sujeito do inconsciente, tal como encontra-se subsumido no texto freudiano e tal como foi explicitado e elaborado por Jacques Lacan (1999), é manifestação evanescente ocorrendo como falha na cadeia significante, falha coincidindo com manifestação de uma formação do inconsciente - um esquecimento, um ato falho, um tropeço, um sintoma.

Quando se propõe, então, que o tratamento psicoterapêutico da depressão se refere a uma perspectiva, uma abordagem clínica levando em consideração o modo de existência do sujeito, o que se pretende manter em perspectiva é um estilo que permita 1) o reconhecimento do estrangeiro enigmático na cadeia significante e 2) um movimento psíquico, um ritmo psíquico regido pelo significante.

Assim, o psicoterapeuta deve tratar a depressão do paciente na temporalidade das representações significantes traduzidas pela linguagem sem esquecer que esse lugar e essa perspectiva, na contemporaneidade, não são nem hegemônicos nem desejados por aqueles que cultivam a produção e a eficácia. 


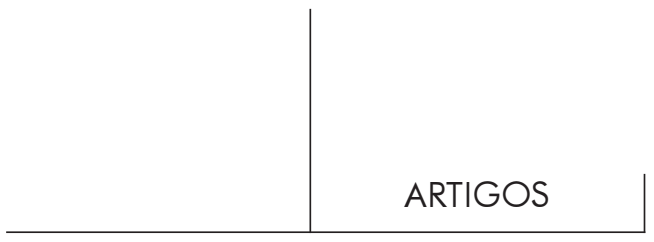

Bibliografia

Aristóteles. $O$ homem de gênio e a melancolia. O problema $X X X, 1$. Trad. do grego, apres. e notas de Jackie Pigeaud. Trad. de Alexei Bueno. Rio de Janeiro: Lacerda, 1998.

Associação Psiquiátrica Americana, Manual diagnóstico e estatístico de transtornos mentais - DSM IV. Porto Alegre: Artes Médicas, 1993.

Berlinck, Manoel Tosta. "Autismo, paradigma do aparelho psíquico", in Estilos da

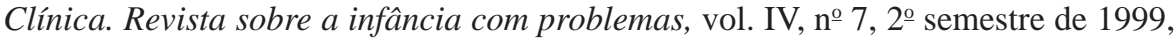
pp. 30-42.

BLoc, G. E. R. (org.). Hippocratic Writings. London: Penguin, 1983.

Bucher, Richard. Depressão e melancolia. Estrutura e classificação dos estados depressivos. Rio de Janeiro: Jorge Zahar, 1979.

Burton, Robert. The Anatomy of Melancholy. London: Penguin, 1997.

FÉdIDA, Pierre. Depressão. Trad. de Martha Gambini. São Paulo: Escuta, 1999.

FreUd, Sigmund. "Luto e melancolia" (1915). ESB, vol. XIV. Rio de Janeiro: Imago, 1969. "O mal-estar na civilização" (1938). ESB, vol. XXI. Rio de Janeiro: Imago, 1969.

Neuroses de transferência: uma síntese. Trad. de Abram Eksterman. Rio de Janeiro: Imago, 1987.

Grinberg, Leon. Culpa y depresión. Estudio psicoanalítico. Madrid: Alianza, 1983.

The Harvard Mental Health Letter, Internet, 1990.

LacAn, Jacques. O Seminário. Livro 5. As formações do inconsciente. Trad. de Vera Ribeiro. Rio de Janeiro: Jorge Zahar, 1999.

Lambotte, Marie-Claude. O discurso melancólico. Trad. de Sandra Refina Felgueiras. Rio de Janeiro: Companhia de Freud, 1997.

Pereira, Mário Eduardo Costa. Pânico e desamparo. São Paulo: Escuta, 1999.

Peres, Urânia Tourinho (org.). Melancolia. São Paulo: Escuta, 1996.

Pessotti, Isaias. Os nomes da loucura. Rio de Janeiro: Ed. 34, 1999.

Rocha, Zeferino. "Desamparo e metapsicologia. Para situar o conceito de desamparo no contexto da metapsicologia freudiana”, in Síntese. Revista de filosofia, vol. 26, no 86 (1999), pp. 331-346.

Roudinesco, Elisabeth \& Plon, Michel. Verbetes sobre melancolia e sobre mania. Dicionário de psicanálise. Trad. de Vera Ribeiro e Lucy Magalhães. Supervisão da ed. bras. de Marco Antonio Coutinho Jorge. Rio de Janeiro: Jorge Zahar, 1998.

SAcKs, Oliver. Tempo de despertar. Trad. de Laura Teixeira da Motta. São Paulo: Companhia das Letras, 1997.

Tellenbach, Hubert. "A endogenidade como origem da melancolia e do tipo melancólico", in Revista Latinoamericana de Psicopatologia Fundamental, vol. II, nº 4, dezembro de 1999, pp. 164-175. 


\section{Resumos}

La psicoterapía con pacientes que se hallan bajo el efecto de antidepresivos revela que esos son relativamente eficazes en la inibición de los síntomas considerados típicos de la depresión. Sin embargo, al mismo tiempo, síntomas considerados típicos de la melancolía no son afectados por esos medicamentos.

Ni la larga y rica tradición psiquiátrica ni la psicoanalítica establecen una diferencia específica entre depresión y melancolía tratandolas, en general, como se hiciesen parte de un mismo campo semántico y por lo tanto siendo utilizadas como sinónimos. Esta tendencia culmina en manuales de psiquiatría, como los DSM-IV y el CID-10, en el cuales el trastorno bipolar es llamado maníaco-depresivo. La melancolía es, así, disolvida en la depresión.

Este trabajo establece una diferencia específica entre depresión y melancolía y describe el campo semántico propio de la depresión.

Palabras llave: Psiquiatría, psicoanálisis, depresión, melancolía, psicoterapía

La psychothérapie avec des patients qui sont sous l'action des antidépresseurs montre que ceux-ci sont relativement efficaces en ce qui concerne à l'inhibition de sumptômes tenus pour typiques de la dépression. Cependant, au même temps, des symptômes tenus pour typiques de la mélancolie ne sont pas affectés par ces médicaments.

Ni la longue et riche tradition psychiatrique ni celle de la psychanalyse établissent une distinction claire et spécifique entre dépression et mélancolie, en les traitant, au contraire, le plus souvent, comme des parties du même champ sémantique - et c'est pour cela qu'elles sont utilisées comme synonymes. Cette tendance atteint son point culminant aux manuels de psychiatrie, comme le DSM-IV et le CID-10, où le bouleversement bipolaire est dénommé maniacodépressiv. La mélancolie reste, ainsi, dissoute dans la dépression.

En partant de cette constatation clinique, ce travail établit une distinction spécifique entre dépression et mélancolie et décrit un champ sémantique propre à la dépression.

Mots clé: Psychiatrie, psychanalyse, dépression, mélancolie, psychotherapie

The psychotherapy with patients that are under the effect of antidepressives reveals that these drugs are relatively efficient for the symptoms inhibition that are typical of depression. However, symptoms considered typical of melancholia are not affected by these drugs.

Neither the long and rich psychiatric tradition nor the psychoanalytic one establish a specific and clear difference between depression and melancholia, considering them as parts of the same semantic field and treating them as synonyms. 


\section{ARTIGOS}

This tendency is most evident in psychiatric manuals as DSM-IV and CID-10, where bipolar disorder is called maniac-depressive. Melancholia is, therefore, dissolved in depression.

Starting from clinical observation, this article establishes a specific difference between depression and melancholia and describes the semantic field of depression.

Key words: Psychiatry, psychoanalysis, depression, melancholia, psychotherapy 